\title{
Impact of Inflation on Labour Productivity in Sri Lanka
}

\author{
Rohini Dunuwita Liyanage \\ Department of Economics, University of Colombo, Colombo, Sri Lanka
}

Email address:

rohinidliyange@gmail.com,rohini@cbsl.lk

\section{To cite this article:}

Rohini Dunuwita Liyanage. Impact of Inflation on Labour Productivity in Sri Lanka. International Journal of Economic Behavior and Organization. Vol. 9, No. 3, 2021, pp. 57-70. doi: 10.11648/j.ijebo.20210903.13

Received: July 29, 2021; Accepted: August 12, 2021; Published: August 19, 2021

\begin{abstract}
Inflation and labour productivity has been a longstanding research interest in developed and industrialized countries compared to developing countries, showing the importance of concept related to efficiency and competitiveness when the economies are growing. Capacity of the economy in Sri Lanka doubled within six years during the period from 2006 to 2012. However, aging populations, raising dependency ratio, lower labour force participation rate, are emphasized as labour force related problems that required to address. Further Sri Lanka has been identified as a country that stuck in middle income trap for a long period of time due to less economic diversification, inelastic and inefficient labour market. In these context, educational reforms to address the skills and knowledge gap in labour market demand and supply, improvement in labour productivity and efficiency-based productivity, are identified to overcome the challenges. This study explores the impact of inflation on labour productivity in Sri Lanka during the period from 2006 to 2020 by employing, univariate Vector Auto Regression model for secondary, monthly seasonally adjusted data. Model was estimated subject to conducting basic test to check unit root and cointegration of the variables. Lag order $16^{\text {th }}$ for the model, was selected subject to lag length criteria, significant of the lag exclusion test, stability test and residual tests to consider the appropriateness of the model. As per the dynamic analysis of the results, labour productivity is strongly impacted by variable itself. Accordingly, previous period realization of labour productivity is associated to increase labour productivity in current period significantly by 0.54 per cent. Further, there is a negative relationship between inflation and labour productivity in short run. Accordingly, one percent increase of inflation in previous two months, are associated to decrease labour productivity by 0.014 and 0.324 on average ceteris paribus. Inverse relationship between variables is supported with the findings in empirical evidences. As per variance decompositions, labour productivity and inflation are forecasted by itself. Therefore, labour productivity and inflation are identified as strongly endogenous and strongly exogenous variables respectively. No granger causality relationships are existed between variables. Negative relationship between inflation and labour productivity is identified that imply, inflation can be effectively used in achieving higher labour productivity. Therefore, suggestions are made to keep a lower level, single digit inflation in enhancing labour productivity.
\end{abstract}

Keywords: Inflation, Labour Productivity, Sri Lanka

\section{Introduction}

There has been a longstanding research interest on what is the impact of inflation on the economic growth and productivity growth. "Inflation is always and everywhere a monetary phenomenon" as per the Monetarism. After the Monetarism, researches identified that impact of inflation on economic activities are higher in the short run. Therefore, maintaining a lower inflation has been one of the main objectives in monetary policy target in short run to achieve other long run objectives including economic growth.
Inflation in simply can be identified as a continuous increase of general price level of a country for a given period of time. Inflation in turn erode the purchasing power of money. However, it is well accepted that lower stable inflation is led to stimulate economic activities. An increase of gross domestic product compared to the previous period quarterly or yearly of a country is identified as economic growth, economic growth is considered as the main indicator of an economy to measure the progress of country in economic, socio and statistical analysis. Productivity can be identified as output input ratio. As per veteran economist "The age of diminished expectations [1]" explained Productivity isn't 
everything, but in the long run it is almost everything. A country's ability to improve its standard of living over time depends almost entirely on its ability to raise its output per worker." It provides basis for consumption, savings, investments, housing, education, poverty reduction and is a vital factor of international competitiveness. Productivity is a measure of efficiency and a competitiveness of a nation as well. As per the production function, production is a function of labour and capital. Labour has been identified as the only one input that has been influence on production in short run. Capital, technology, and population growth are other factors that has been identified to influence on production in the long run. Thus, labour productivity is one of indicator that shows how productively the labour has been used in the production process. Therefore, Economic growth and productivity growth can be identified the ultimate objectives in policy formulating in the economic development process of a country.

As per the international evidence "Some international evidence on output-inflation tradeoffs [2]" suggest a negative relationship between variables. Many empirical studies have been reconciled the theoretically negative relationship between inflation and productivity. Price stability or maintain a stable lower-level inflation is a short-term objective of the monetary authorities of a country. In the stabilization policies, which include fiscal and monetary policy, more attention has been paid on keeping a lower - level inflation to achieve long term objectives of an economy. Some developed countries have converged to maintain a lower level of inflation that has defined below 2 per cent. As per the theory, inflation impacts negatively on productivity due to the impact of worker purchasing power, motivation and effort. Further, inflation impacts on firms' investments plans, capital depreciation rates and substitution of factor inputs that is capital for labour. Inflation and real wages related study "Modelling UK inflation [3]" concludes that inflation responses to many parts of an economy including labour cost and labour market. Negative relationship between inflation and labour productivity has been established in majority of empirical analysis. Economists are in the view of that a lower-level inflation below 2 percent is encouraging economic activities. A study on "Does inflation lower productivity? Time series evidence on the impact of inflation on labor productivity in 12 OECD nations [4]" examined whether there is an empirical support to reduce already low rate of inflation to increase labour productivity growth and economic growth. Finding did not support the view of that, further reductions in inflation from already low single-digit levels that would have a positive impact on labour productivity growth for major industrial countries. Therefore, it is a well-established fact that there must be a stable lowerlevel inflation to stimulate economic activity and growth, while a higher level of inflation is harmful to encourage economic activities. Several arguments pointed out that this inverse relationship is 'spurious' due to cyclical movements of the variables that are based on the statistical concepts.

Causal relationship and direction of causality among inflation and labour productivity is addressed in different theory and empirical studies. Productivity granger cause inflation, in standard economic theory, it describes as productivity growth is exogenous and therefore, higher productivity leading to lower inflation and increase aggregate supply. In contrast, inflation granger causes productivity, as per the other alternative theoretical views. However, "Inflation and economic growth: a multi-country empirical analysis [5]" examined that vast majority of countries having uni-directional or bidirectional causality is belongs to the industrial group.

In Sri Lanka, labour productivity as measures by using GDP divided by employed population has been improved in line with the structure of the economy that has been dominated by service sector. Accordingly, labour productivity is higher within the service sector compared to the labour productivity in industry and agriculture sector. Further, structural transition of the economy has been shifted to service sector instead of industry to service sector. This shows less usage of the natural resources of the country and not improving further processing of such product, catered by the industry sector. This could be a challenge to ensure the independency of the country in terms of food security. Further, labour flows are moving to high productive service sector from other two sectors. Continuation of this labour flows moving could be adversely impacted to decline labour productivity in services sector while other sectors are suffering deficiency of labour. Therefore, strengthening the structure of the economy using domestic resources and value addition should be focused on policies in medium and long run basis.

As per "Sri Lanka: fostering workforce skills through education: employment diagnostic study [6]" Sri Lanka has entered a demographic transition characterized by lower birth and death rates. This result working-age population to decline with an aging of society and the rising age dependency ratio. In order to sustain the expenses, a higher growth rate has to be achieved to cushion the requirement of pension, health and other expenses. Sri Lanka is categorized as an upper middle-income level country by the World Bank based on the per capita gross national income in 2017 . The category again has downgraded to lower middle-income country in 2020 considering revisions to national account methods and adjustments to keep income classification thresholds fixed in real time. However, it takes a long time to reach with the upper-level income compared to the emerging market economies. Therefore, Sri Lanka is in challenge with the stuck in Middle-Income Trap (MIT) that has to be overcome through efficiency base productivity which comes by together with technology and innovations. Further, "Middleincome trap: Review of the conceptual framework [7]" pointed out that this, stuck in MIT could be led by decreasing of the productivity due to the factors like less economic diversification, inelastic and inefficient labour market, inefficient financial market, outdated infrastructure facilities, inefficient institutions and less innovations. As per the above categorization, Sri Lanka belongs to the lowest level of the economic diversification and inefficient labour market. Therefore, in order to overcome this challenge, the next level 
would rely on the efficiency driven productivity growth. Therefore, in all these scenarios, an increase in labour productivity is essential to sustain economic growth and thereby achieving higher standard of living, wellbeing of the nation and to maintain the economy's competitiveness.

Inflation in Sri Lanka has been reported as a single digit level with declining trend. Keeping a lower-level inflation is one of the short-term target in monetary policy implementation towards achieving medium- and long-term objectives. Inflation was substantially higher during the period from 2006 to 2010 period followed by the restrictions and security reasons imposed on Northern eastern conflict. However, economic growth also has been reported at a satisfactory level showing the resilience of the economy to the domestic and external shocks before 2010. Lower inflation has been reported after 2010 onward 2020 that shows achievements of the short-term objective of the monetary policy conducted by the Central Bank of Sri Lanka. Economic growth contracted notably in Sri Lanka by 3.6 percent in 2020 due to the moving restrictions imposed to mitigate the spread of COVID 19 pandemic which has been negatively impacted to continuous performance of other economies as well. Anyway, economic growth has been limited in recent years after 2015, challenging to the negative relationship between inflation, economic growth, and labour productivity. Therefore, this paper is aimed to find the relationship between inflation and labour productivity in Sri Lanka for the period from 2006 to 2020. Direction of causality relationship between variables are also examined for better prediction of variables in forecasting variables using lag values of other variables than using the variable alone. Secondary sourced, monthly data are employed to analysis quantitative data sample spanning from 2006 to 2020 . VAR model is employed as appropriate model subject to the statistical properties of time series data. This paper is structured to section ii for literature review, section iii to discuss methodology, results, and discussion in section iv and finally conclusion and recommendations are made in section iv.

\section{Literature Review}

Theoretical literature is enriched with studies related to inflation, economic growth and labour productivity since these are macroeconomic variables. Inflation and economic growth have been focused with much attention compared to inflation and labour productivity due to the relevancy of inflation and economic growth as direct objective in conducting monetary policy while enhancing productivity and efficiency are in long term policy interest. Further inflation and economic growth have been well documented compared to the inflation and labour productivity that have been limited to developed and emerging market economies. As per the theory, there is negative relationship between inflation and economic growth. Factors affecting to enhance production are labour and capital. Therefore, contribution to the literature in terms of inflation and growth, inflation and labour productivity is utmost important since there is a few and outdated prior studies that were found with respect to inflation and economic growth, inflation and labour productivity in Sri Lanka. There are theories of inflation, economic growth and productivity that are separately described in literature. Therefore, this study considers literature on inflation and labour productivity. Further, empirical studies on inflation and economic growth also considered in literature as, the gross domestic product is a main variable in constructing labour productivity. Therefore, review of empirical literature is expected to discuss mainly relating to the relationship between inflation and economic growth, inflation and labour productivity separately.

\subsection{Inflation and Economic Growth}

There has been an ever-growing research interest on inflation and economic growth irrespective of developed, developing countries. After the monetarism, inflation has been identified as a factor that can be influence on economic activities in short run. Further inflation has been considered as an adjustment tool that distribute the benefit of economic growth within the country through price signaling. As a result, lower inflation has been kept as an anchor in conducting monetary policy operations in many countries subject to different policy regimes.

A broad-based study "Inflation and economic growth: a multi-country empirical analysis [5]" is conducted for 70 countries of major industrialized, newly industrialized and developing countries using annual data spanning from 1960 to 1989 . Several conclusions were made in the study as the relationship between inflation and the economic growth is non uniform across countries. 40 per cent of countries shows no causal relationship between variables. Majority of countries that shows causal relationships between variables are belongs to industrial group. Finally low inflation regime will benefit to redistribute growth opportunities and benefits towards industrialized countries and away from developing countries. According to the finding of this, it is clear that inflation is helpful industrialized countries that have higher economic growth to redistribute growth opportunities within the countries. Further, causal relationship between inflation and growth also possible in developed countries as in said study. Another study for Fuji "Relationship between inflation and economic growth [8]" concluded that a weak negative correlation exists between variables while change in output gap shows significant bearings. Causality relationship runs from GDP to inflation.

Nonlinear relationship between inflation and economic growth has been also examined in several studies. A study "Nonlinear effects of inflation on economic growth [9]" examined by giving a structural break at 8 per cent of inflation, there is no any growth effect of inflation below 8 percent or may be a slightly positive effect on growth. Further inflation above 8 per cent gives significant effect on growth that is extremely powerful. Further, another study "On the nonlinear relationship between inflation and economic growth [10]" concludes that the non-linearity relationship between inflation and economic growth is sensitive to the several facts that level 
of financial development, capital accumulation, trade openness and government expenditure. A study "When does inflation hurt economic growth? in Different Nonlinearities for Different Economies [11]" found that effect of inflation on growth changes are substantially higher, when inflation is higher. Further these nonlinearities are influenced differently for industrial and developing countries. The study established a threshold level that inflation is negatively impacted when the growth is around 8 per cent for industrial economies, while 3 per cent or less for developing countries. It further explains that failure to account for nonlinearity biases downward the estimated effects of inflation on growth. Finally, it concludes, studies conducted by mixing both industrial and developing economies also produces unreliable results.

Empirical studies found for Asian countries also, on inflation and economic growth. A study covering six South Asian countries "Inflation and its impact on economic growth: Evidence from six South Asian countries [12]" concluded that there is a high positive correlation between inflation and economic growth for all six countries. As per the cointegration relationship, long run relationship exists for Malaysia while other countries show short run relationships between variables. Further, "Inflation and economic growth: evidence from four south Asian countries [13]" the study conducted including Sri Lanka using annual data to an error correction model. Findings were that there is a long run positive relationship between GDP growth and inflation for all four countries. Moderate inflation is helpful to growth, but faster economic growth feeds back into inflation. Therefore, these countries are on a knife-edge. Supporting to the positive relationship between inflation and economic growth "Inflation and economic growth: Evidence from Pakistan [14]" examined that inflation and economic growth is positively related while unidirectional causality is existing from inflation to growth. Threshold level up to 9 per cent of inflation is growth benefited while above 9 per cent inflation turns to lower economic growth in Pakistan. Therefore, the paper recommends a single digit inflation for Pakistan to enrich economic growth. Study conducted for Sri Lanka "Inflation and economic growth in Sri Lanka [15]" with view that the inflation and economic growth relationship is not in line with expected theoretical movements. But it concludes that both inflation and economic growth shows a long run nexus, appearing a negative sign for the period from 1970 2014 using annual data. In contrasting to the findings related to developing countries mentioned above, "Impact of inflation on economic growth in Sri Lanka... [16]" concluded that there is a long run negative and significant relationship between inflation and economic growth in Sri Lanka for the period 1988-2015. Anyway, finding of this study is questionable compared to the findings of the other research covering Sri Lanka.

One study found on inflation, economic growth, and labour productivity when prices are almost unchanged "Inflation, output and labour productivity when prices are changed infrequently... [17]" findings were that when inflation is relatively stable, effect of inflation on output depends on the form of profit and demand function. Further with some specifications, inflation increases output but reduce labour productivity. Therefore, it mentioned that inflation is however, an inefficient way of rising growth since labour productivity is declined.

\subsection{Inflation and Labour Productivity}

Interest on inflation and productivity has been a growing concern with the stabilization policies sets under the fiscal and monetary discipline. Inflation has been a major, short term objective while productivity improvements and economic growth has been the long-term objective. Paper "minimum inflation rate for Euroland ... [18]" demonstrates to keep a minimum aggregate inflation as 0.94 percent in Euro countries and the limit extension given up to 1.5 per cent for Eastern Europe countries to ensure price stability in conducting a common monetary policy. However, keeping a target rate of lower inflation is related some issues in the long run "The long-run effects of low inflation rates... [19]" has been observed supporting with lower inflation and lower real wages together goes with a long run relationship to a higher unemployment rate.

Economists' argument on inflation and productivity can be identified as inflation is negatively impacted on productivity through price signaling to economic agents and sectors. First, inflation impacts on worker purchasing power, mix of factor inputs and to the investment's plans. Worker purchasing power is from labour supply side factor and other two are from production point of view. Effect on inflation "Inflation, tax rules and the accumulation of residential and nonresidential capital... [20]" examined and found that given the existing tax structure, inflation lowers the real return on capital. Thus, findings of the empirical literature are in line with theory and sometimes provide different views from the theory. Accordingly, several studies [21-24] conclude that there is a negative significant relationship between inflation and labour productivity whilst other studies [23, 25-27] explain number of reasons for the existence of negative relationship between inflation and labour productivity. These reasons impact to decline purchasing power of wages and reduce motivation to work, cause an inefficient mix of factor inputs, distort the informational content of price signals that firms could be more likely to select other optional factor inputs, invest in inefficient investment plans, encourage firms to increase cost of inventories for unproductive buffer stocks that may reduce the expenditure on research and development. Further, inflation causes to reduce the tax deductions for depreciation and thereby raises the cost of rental capital which might cause a reduction in capital accumulation. Therefore, in this way, productivity can be impacted by changing real wages also in addition to inflation. According to $[28,29]$ number of studies, it is evident that the possible avenues for inflation may adversely impact on productivity in the long run are, inefficient mix of factor inputs, increasing unproductive buffer stock and thereby reduction of the cost on Research and Development (R \& D) expenditure.

Quantified strong relationship has been identified [30] and 
found as, one per cent increase in labour and Total Factor Productivity (TFP) reduces Consumer Price Index (CPI) inflation by $0.07-0.08$ per cent and $0.37-0.44$ per cent respectively. This study has been considered both labour productivity and total factor productivity. Further the study suggests that the productivity-inflation nexus became stronger in Korea during the Asian financial crisis, and this was largely due to structural reforms and technological progress. Negative relationship between variables [31] are also suggested for 15 European countries using Vector Error Correction Model (VECM) technique.

Relationship based on short run and long run wise also has been analyzed and [28] confirmed a long run negative relationship between inflation and productivity for seven countries out of fifteen country sample. Impact of inflation on industry level productivity was examined [32] for Australia and find a significant result with inflation and productivity for concentrated industries that managed by large firms. Further, it shows that this relationship varies by the industry and the negative effect of inflation on productivity does not operate through reduction in capital accumulation. Effect of inflation on mining sector productivity was examined and [33] pointed out that domestic inflation has a small but a negative relationship with mining sector productivity. Causal relationship from inflation to mining sector productivity also noted, support with inflation granger cause productivity.

Among few studies in empirical literature covering Asian counties, [34] conducted a study covering nine Asian countries including Sri Lanka. Study concludes, inflation productivity growth relationship is found to be non-uniform, as the evidence of unidirectional, bidirectional and no causality between variables is differed and significant only for some countries. Main findings are grouped in to three categories of which no causality effect between inflation and productivity growth category is valid for Sri Lanka for the period from 1966 to 1997.

Several studies could be founded regarding inflation and productivity relationships with mixed findings and arguments. One study "Does inflation reduce productivity... [35]" shows the negative relationship between inflation and labour productivity and argues that it is difficult to conclude the way that higher inflation causes productivity to fail. This conclusion made for the US, covering the period 1949-94 post war evidence. Another study "Stylized facts and stylized illusions: inflation and productivity revisited... [36]" concludes that there is no evidence for any connection between inflation and productivity growth in the long run while there is a strong connection between inflation and productivity growth in the short run and it depends entirely on the cointegration and stationarity of the variables. Further, discussing with multifactor productivity [37] concluded that inflation's impact on multifactor productivity growth was so minor that it did not show up as statistically significant in the analysis. Thus, relationship has been deciding depends on the integration level of the variables and has been identified the relationship between inflation and productivity as 'spurious' due to cyclical movements of the variables. Study [38] also argued that there is no important relationship between inflation and productivity for low inflation countries. According to their study, bivariate relationship between inflation and productivity is 'spurious' due to inflation and productivity is integrated in different order. Same researcher, [39] examined on the inflation and productivity relationship in Poland from 1991-1998 concluding the same, "the relationship between inflation and productivity is spurious". Supporting with the mix findings, it has been [4] concluded that there is no evidence of a consistent relationship between inflation and productivity growth regarding either sign or magnitude. Further, the study concluded that there is an unidirectional causal relationship running from productivity to inflation. Further, the study [26] argues that relationship between inflation and productivity cannot be accepted due to cyclical movements between two variables. Thus, it is noted that debatable and mixed findings are evident in empirical literature on the relationship between inflation and labour productivity.

\subsection{Concerns on Empirical Literature}

In conclusion to the relationship between inflation and economic growth, there have been enriched empirical literature on the relationship between inflation and economic growth irrespective of developed, developing countries. Inflation and economic growth are negatively related as per the theoretical literature where mix findings can be explored in empirical literature. Inverse relationship between variables can be examined with respect to developed countries in line with the theory and relationship is diverged with respect to developing countries as explored in empirical evidences. Further, causality and directional relationship also can be noted between variables for developed and industrialized economies. Several studies pointed out, a threshold limit of 8-9 per cent or single digit inflation where has been responded positively with economic growth for developing countries. Anyway, inflation is still using an effective policy tool in conducting monetary policy referring to inflation is always and everywhere a monetary phenomenon. Annual data have been used by majority of studies while data frequency has changed to quarterly or monthly. Further, findings of the study [16] concludes for existing a negative significant relationship between inflation and economic growth for Sri Lanka is questionable when compared with the results found in other studies for similar countries and similar study period.

With respect to the relationship on inflation and labour productivity, lack of consensus can be noticed in relation to the literature on inflation and labour productivity. Accordingly, majority of the empirical relationship between inflation and labour productivity is negative. Findings of the other studies are diverged from negative to zero and towards an insignificant and spurious relationships. Causality between inflation and productivity also runs both sides, from inflation to productivity, productivity to inflation. Methodology used in early studies on inflation and labour productivity was the ratios, regressions analysis and time 
series analysis. Small sample used for the analysis led to distort the power of the test and mislead conclusions which have to be representative. Cointegration and causality also have been tested. There is an argument ends up stating that the relationship between inflation and productivity is 'spurious' which was based on the different order of integration and cyclical movements of the variables. One reason that can be pointed out for endless arguments that are based on the statistical concept related to time series data. Empirical literature on inflation and labour productivity has been examined with more attention due to relevancy on policy implication. In case of Sri Lanka, empirical literature is rare in this regard. Therefore, this study is conducted to fill the existing gap in literature with respect to empirical and methodological aspects. Specifically, in order to contribute the literature on inflation and economic growth, inflation and labour productivity in Sri Lanka. Methodology is adopted using quantitative, secondary monthly data to address the concerns on frequency of data. Study covers the period spanning from 2006-2020. Further, direction of causality also examined for the better prediction of variables using lag value of another variable. Finally, conclusions and recommendations are made to enhance economic growth and labour productivity based on the results of the study.

\section{Methodology}

As per the theoretical and empirical literature, inflation has a negative impact on economic growth and labour productivity. Based on the empirical literature, one model is estimated to examine the two bivariate relationships among variables. Accordingly, based on the economic theory and empirical studies, a model on inflation and labour productivity (Gross Domestic Product divided by employed population) is considered to estimate the relationships among variables. Inflation is the independent variable while labour productivity as dependent variable for the model. Colombo Consumer Price Index (CCPI) is used to measure the inflation, Gross Domestic Product at constant prices is used to measure GDP growth while labour productivity is constructed using GDP/employed population. Data are obtained through the secondary sources of Central Bank of Sri Lanka (CBSL) and Department of Census and Statistics (DCS). Accordingly, Secondary sourced quantitative, monthly data are employed for the analysis, period spanning from 2006 to 2020 . E views 10/11 software is used for the data analysis.

\subsection{Selecting an Appropriate Model}

Selecting an appropriate model to analyse time series data should be carefully decided since time series data varied with the time and therefore its mean, variance and covariance are subject to change with the time which we call nonestationarity in simple. This could be sometimes led to have an equilibrium relationship in long run among variables. In model building of time series data, it is a requirement to estimate the model subject to Best Linear Unbiased Estimate (BLUE) properties [40] to represent the population from the sample. Regarding this, ${ }^{1}$ Gauss Marko Assumptions for Ordinary Least Square (OLS) regressions should be fulfilled in the process of estimation. Changing the mean, variance and covariance over the time series data, are led to violation of some of the Gauss Marko assumptions under the OLS. As [41] demonstrated that if two independent, nonstationary series are regressed on each other, the chances for finding a spurious relationship are high.

With the concern of the stationarity in time series data, estimating the OLS is led to spurious regressions, serial correlation, autocorrelation, multicollinearity, and endogeneity problem since many time series are endogenously related with each other. In order to over-come this errors, multi equation time series approach model for endogenously related variables can be estimated using the Vector Auto Regression (VAR) for stationary variables, Vector Error Correction Model (VECM) for none-stationary, cointegrated variables are used. Therefore, in this study, VAR is employed as appropriate model subject to the stationary and cointegration test of the variables.

\subsection{Measuring Labour Productivity}

In simple, labour productivity can be identified as output input ratio. Labour productivity is separately measured among other productivity measures due to the importance in economic and statistical analysis of a country and as a measure of efficiency and competitiveness as well. There are several ways to calculate the productivity ratio in an economy. As per [42] guidance, measures for output are Gross Domestic Product (GDP) or Gross Value Added (GVA). Total number or Hours Work (HW) or Employed Population are used as inputs. In this study, Labour Productivity (PDCT) is constructed using Gross Domestic Product at constant prices, divided by Employed Population (GDP/EP). Data source for both GDP and EP are obtained from Department of Census and Statistics.

$$
\frac{\mathrm{GDP}}{E P}=P D C T
$$

GDP: Gross Domestic Product, $2010=100$, quarterly data by the DCS.

EP: Employed Population as given by labour force indicators, quarterly data.

CCPI: inflation as measured by price indices $2013=100$, monthly data.

In the data series, quarterly data was transformed to monthly data in E-views using the linear trend. Further the independence variables CCPI were rebased as $2010=100$ to

\footnotetext{
1 The regression model is linear in the coefficients and the error term. The error term has a population mean of zero.

All independent variables are uncorrelated with the error term, i.e. explanatory variables are deterministic (non-stochastic) and exogenous or no endogeneity. Observations of the error term are independently distributed and uncorrelated with each other or no autocorrelation/ serial correlation.

The error term has a constant variance or no heteroscedasticity.

No independent variable is a perfect linear function of other explanatory variables or no multicollinearity.
} 
compatible with each other.

Logarithmic transformation of the equations are as follows:

$$
\beta_{0}+\beta_{1} l C C P I_{t}+e t=l P D C T_{t}
$$

Coefficient of $\beta 1$ for inflation shows elasticity of CCPI growth. Labour's productivity elasticity with respect to changes in LCCPI and is expected to be negative as per the empirical literature. Basic tests to be followed for time series data, before estimation of the model, can be described as below.

\subsection{Basic Tests for Time Series Data}

In this study, quantitative methods, multivariate equation model is employed to analyse the time series data. Time series data has special properties since data is changing with the time. Such properties are autoregressive, moving average and seasonal dynamic process due to past values influence future values. Time series data are varying with the time. This influences to change the mean, variance and covariance which are called nonstationary of the variables. A paper [41] demonstrated, if two independent, nonstationary series are regressed on each other, the chances for finding a spurious relationship are very high. Further, many time series data are endogenously related, which we can model with multi-equation time series approaches, such as Vector Auto Regression (VAR). In this study, VAR is estimated after employing basic diagnostic tests to check the stationarity and cointegration/existing a long run relationship among variables. Basic tests to be followed before estimation the model is unit roots test, cointegration test, lag selection criteria and significance of the lag length. Stability of the model and the goodness of the fit is tested using stability test, serial correlation LM test and heteroscedasticity tests in e-views.

\subsection{Unit Root Test}

Since time series data are used for the analysis, basic test to check the stationarity of the variables should be performed. Forms of stationarity are weak, strong and super [43]. In order to find whether the series are integrated of order (0) or I (1), Dickey-Fuller (ADF) $(1979,1981)$ and Phillips-Perron (PP) (1988) tests are used. Based on the unit root test, integration level of the variables is decided. Whether the variables are stationary at order I (0), I (1) or I(d). for time series data that are changing with the time, variables may not be stationary at level and might go for the next level cointegration test to check whether there is a long run relationship among variables.

\subsection{Cointegration Test}

Cointegration is associated with the long run relationship among the variables. If all variables are stationary or integration in order I (0) or level, then it is decided, there is no cointegration relationship among variables and can perform a Vector Auto Regression (VAR) model. In order to check whether there is a long run relationship among variables, cointegration test is performed. There are two ways of checking cointegration. For two variables/ series of integrated order I (1) are tested [44] using two step residuals tests. First, OLS regression is estimated for the variables. Then it is required to generate a residual series of the regression and check the stationary of the residual series. If the residual series is stationary at level, with level one variables, it is considered to have a long run equilibrium among variables or cointegration relationship in the model. When the OLS having a such cointegration, Error Correction model is estimated. Otherwise, VAR models can be estimated, using first difference of the variables. In this model, Cointegration is tested using the Angel granger two step method.

\subsection{Lag Length Criteria}

Determining the lag length of autoregressive process for a time series are a decisive econometric exercise. Proper lag order should be used for model since more lags are related to change the degrees of freedom, statistically insignificant coefficients and multicollinearity related problems while few lags cause specification errors in the model. Information criterion for lag length selection in determining the autoregressive models are Akaike's information criterion (AIC) and Final Prediction Error (FPE). As per the study [45], most economic sample data can seldom be considered "large" in size, AIC and FPE are recommended for the estimation of the autoregressive lag length. In order to select a proper lag length based on information criteria, lag order selection criteria, and the significant of the lag exclusion test are performed.

\subsection{Granger Causality Test}

Causality test indicates correlation between two variables. However, it does not indicate the direction of the relationship. In some cointegration relationship towards the equilibrium in the long run, sometimes, it does not necessarily mean the causation. In order to find the direction of the relationship, Granger causality test is used. Direction of causality is useful for the prediction purposes. If $A$ is helpful explaining B, it is called, A can be Granger cause of B and vice versa and therefore, A can be used for better prediction of $\mathrm{B}$ than using $\mathrm{B}$ alone. If Granger causality exists between variables, null hypothesis of no causality between variable is rejected and the alternative hypothesis is accepted at $5 \%$ or $1 \%$ significant level. Causal relationships in models are tested using pairwise/Wald granger causality test.

In this study, a bivariate VAR model is estimated after the basic test to check the time series properties of the data, selecting a lag, significant of the selected lag. Results of VAR model is explained by means of impulse response functions and variance decomposition. Before the VAR model estimation, diagnostic tests and after the estimation, stability test and residual tests are performed to measure the appropriateness of the model. 


\section{Results and Discussion}

\subsection{Results of Basic Tests}

Relationship between inflation, economic growth and labour productivity is estimated using multivariate time series analysis techniques subject to the results of the basis tests are discussed. In order to check the time series properties of the data, unit roots tests are performed using $\mathrm{ADF}$ and $\mathrm{PP}$ at level and level 1 , at 5 per cent significant level for the seasonally adjusted variables. Results of the unit root tests for seasonally adjusted variables are summarized in the below table 1 .

Table 1. Results of the unit root tests.

\begin{tabular}{llllll}
\hline Variables & ADF test $@$ level & ADF test @ level 1 & PP test $@$ level & PP test @ level 1 & stationary \\
\hline \multirow{2}{*}{ PDCT } & 0.7449 & 0.0007 & 0.7782 & 0.0000 & \multirow{2}{*}{ level 1} \\
& -1.0221 & -4.2790 & -0.9258 & -11.0006 & \\
CCPI & 0.4481 & 0.0000 & 0.4403 & 0.0000 & @ level 1 \\
\hline
\end{tabular}

Accordingly, all variables are identified as stationary at their first difference in both ADF and PP test statistics at 5 per cent significant level.

Cointegration test should be performed after finding the all variables are stationary at level one in unit root testing.
Results of the cointegration test performed using Angel granger two step method are given below. First, OLS regression is estimated and then unit root test of the error term is tested by generating a residual series of the regression.

Table 2. Results of the cointegration tests.

\begin{tabular}{|c|c|c|c|c|c|}
\hline Residual Series & ADF@level & ADF @ $1^{\text {st }}$ difference & PP@level & PP@ $1^{\text {st }}$ difference & Integration level \\
\hline Recid 01 & -2.301738 & -3.603132 & -2.198172 & -12.48482 & Integrated at $1^{\text {st }}$ \\
\hline Resid 01 & 0.1727 & 0.0067 & 0.2078 & 0.0000 & difference \\
\hline
\end{tabular}

Test statistics at 5 per cent of significant level.

As per the results of the cointegration tests, results of the unit roots test conducted for the error terms (resid 1) created through the Ordinary Least Squared (OLS) regression is stationary at their $1^{\text {st }}$ difference. Accordingly null hypothesis of the (resid 1) has a unit root at the $1^{\text {st }}$ difference of the variable for 5 per cent significant level cannot be rejected and therefore cointegration is not in the variables. Therefore, univariate VAR model is estimated using the $1^{\text {st }}$ difference of the variables subject to the requirement under lag order selection criteria, significant of lag exclusion test, stability test and residual test to ensure the appropriateness of the model.

\subsection{Estimating the VAR Model}

Relationship between inflation and labour productivity in Sri Lanka is estimated using Univariate VAR model for the variables integrated at $1^{\text {st }}$ difference and in the absence of cointegration under the Engel Granger two step method.

A proper lag order for the model is selected using information criteria given as LR: sequential modified LR test statistic (each test at 5\% level), FPE: Final prediction error, AIC: Akaike information criterion, SC: Schwarz information criterion, HQ: Hannan-Quinn information criterion under the lag order selection criteria as given below.

Table 3. Results of lag order selection test.

\begin{tabular}{|c|c|c|c|c|c|c|}
\hline Lag & $\log L$ & LR & FPE & AIC & SC & HQ \\
\hline 0 & 987.1753 & NA & $1.79 \mathrm{e}-08$ & -12.16266 & -12.12454 & -12.14718 \\
\hline 1 & 1001.604 & 28.32275 & $1.57 \mathrm{e}-08$ & -12.29141 & $-12.17705^{*}$ & -12.24498 \\
\hline 2 & 1009.965 & 16.20630 & $1.49 \mathrm{e}-08$ & -12.34525 & -12.15466 & -12.26787 \\
\hline 3 & 1018.050 & 15.47096 & $1.42 \mathrm{e}-08$ & -12.39568 & -12.12885 & $-12.28734 *$ \\
\hline 4 & 1020.183 & 4.029808 & $1.45 \mathrm{e}-08$ & -12.37263 & -12.02957 & -12.23334 \\
\hline 5 & 1021.638 & 2.711518 & $1.50 \mathrm{e}-08$ & -12.34121 & -11.92191 & -12.17097 \\
\hline 6 & 1023.584 & 3.579027 & $1.54 \mathrm{e}-08$ & -12.31585 & -11.82031 & -12.11465 \\
\hline 7 & 1024.346 & 1.383183 & $1.60 \mathrm{e}-08$ & -12.27587 & -11.70410 & -12.04372 \\
\hline 8 & 1025.744 & 2.503084 & $1.65 \mathrm{e}-08$ & -12.24375 & -11.59574 & -11.98065 \\
\hline 9 & 1031.155 & 9.552495 & $1.63 \mathrm{e}-08$ & -12.26117 & -11.53692 & -11.96711 \\
\hline 10 & 1031.700 & 0.948573 & $1.70 \mathrm{e}-08$ & -12.21852 & -11.41803 & -11.89351 \\
\hline 11 & 1035.564 & 6.630934 & $1.70 \mathrm{e}-08$ & -12.21684 & -11.34011 & -11.86087 \\
\hline 12 & 1061.435 & 43.75702 & $1.30 \mathrm{e}-08$ & -12.48685 & -11.53389 & -12.09993 \\
\hline 13 & 1071.570 & 16.89175 & $1.21 \mathrm{e}-08$ & -12.56259 & -11.53339 & -12.14472 \\
\hline 14 & 1073.481 & 3.137350 & $1.24 \mathrm{e}-08$ & -12.53680 & -11.43136 & -12.08797 \\
\hline 16 & 1096.830 & $10.77859 *$ & $1.03 \mathrm{e}-08 *$ & $-12.72630 *$ & -11.46839 & -12.21557 \\
\hline 17 & 1097.487 & 1.029510 & $1.08 \mathrm{e}-08$ & -12.68502 & -11.35088 & -12.14334 \\
\hline
\end{tabular}


Accordingly, as per the given lag order section criteria, lag order $16^{\text {th }}$ is selected based on AIC, FPE and LR criteria to avoid specification errors of the model, insignificant coefficients, and multicollinearity. Further, it is required to check whether above selected lag order $16^{\text {th }}$ is significant using lag exclusion test, results are given below.

Table 4. Results of lag exclusion test.

\begin{tabular}{llll}
\hline Lag & DLPDCT & DLCCPI & Joint \\
\hline Lag1 & $40.85170[0.0000]$ & $12.00327[0.0025]$ & $52.62223[0.0000]$ \\
Lag2 & $5.113030[0.0776]$ & $2.260143[0.3230]$ & $7.442268[0.1143]$ \\
Lag3 & $35.89120[0.0000]$ & $0.860079[0.6505]$ & $36.81708[0.0000]$ \\
Lag4 & $9.065929[0.0107]$ & $1.654605[0.4372]$ & $10.68681[0.0303]$ \\
Lag5 & $1.525404[0.4664]$ & $0.326887[0.8492]$ & $1.860709[0.7614]$ \\
Lag6 & $0.027470[0.9864]$ & $0.907914[0.6351]$ & $0.934526[0.9196]$ \\
Lag7 & $0.779895[0.6771]$ & $0.427970[0.8074]$ & $1.218299[0.8751]$ \\
Lag8 & $0.158524[0.9238]$ & $0.805654[0.6684]$ & $0.970276[0.9143]$ \\
Lag9 & $1.965747[0.3742]$ & $1.964262[0.3745]$ & $3.912335[0.4180]$ \\
Lag10 & $1.217321[0.5441]$ & $0.014113[0.9930]$ & $1.229701[0.8732]$ \\
Lag11 & $3.053659[0.2172]$ & $6.674911[0.1541]$ \\
Lag12 & $3.594414[0.1658]$ & $4.670524[0.0968]$ & $81.20954[0.0000]$ \\
Lag13 & $76.35333[0.0000]$ & $2.386132[0.3033]$ & $29.95841[0.0000]$ \\
Lag14 & $27.67097[0.0000]$ & $1.125697[0.5696]$ & $2.375476[0.6671]$ \\
Lag15 & $1.234409[0.5395]$ & $0.408240[0.8154]$ & $36.32164[0.0000]$ \\
Lag16 & $35.95841[0.0000]$ & $4.303012[0.1163]$ & $11.24780[0.0239]$ \\
\hline
\end{tabular}

In order to consider the selected lag order for the model, the lag should be significant in the lag exclusion test for variables jointly. Accordingly, lag order $16^{\text {th }}$ is jointly significant at lag exclusion test since $p$ value is lower than 0.05 significant level. Therefore, univariate VAR is estimated using lag order $16^{\text {th }}$ to consider the dynamic effects of the variables.

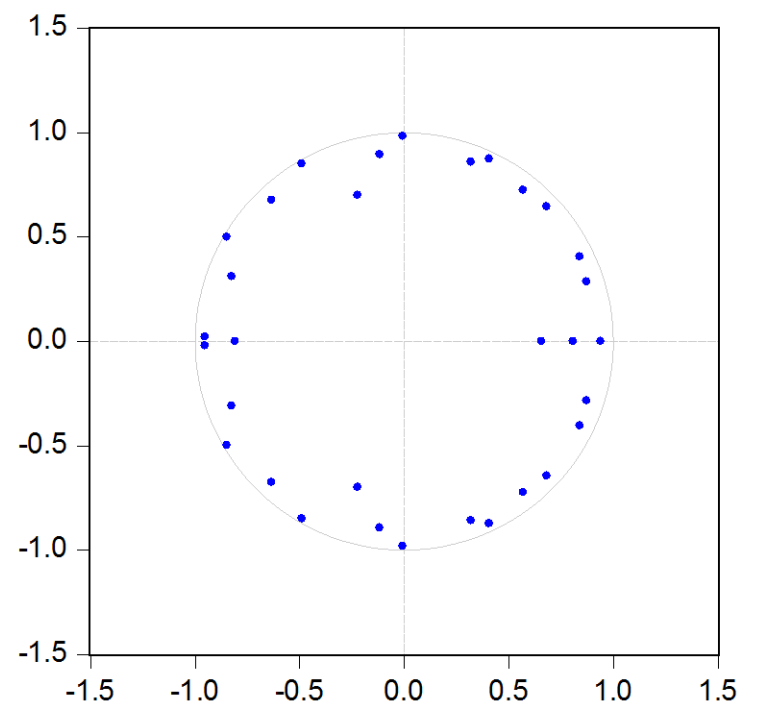

Figure 1. Inverse roots of the AR characteristics polynomial.

\subsection{Other Empirical Tests}

Under the empirical tests, stability test to check the stationarity of the model and the residual tests to examine the autocorrelation, serial correlation, heteroscedasticity is conducted to ensure the non-violation of the assumption under the Gauss Markov Theorem. Stability test was performed to check the stability of the estimated model. Autoregressive (AR) root table and autoregressive root graph is used to check the stability of the model. As per AR root table, all roots are less than one in values implying that no roots lie outside the unit circle given in figure 1 .

Accordingly, all roots lie within the unit circle and therefore, VAR model satisfies with the stability or stationary conditions. Therefore, the impulse responses can be reasonably used to analyse the dynamics effects of the variables.

Correlograms are considered under the residual test that represents the pairwise cross correlation of the estimated residuals for the given number of lags. Correlograms in residual are used to detect the autocorrelation while serial correlation LM test were used to check the serial correlation of the variables. Correlograms of the model estimated is given below.

Accordingly, variables are not continue with its own past and future values or autocorrelation problems since there is no any spikes that lie outside the bounds of 2 standard errors. This is further tested using the residual series of the model, resuls are given below.

Accordingly, the correlograms has no spikes at any lags since $Q$ statistics are not significant at higher $\mathrm{p}$ value than 0.05 significant level, indicating no auto correlation in the residuals. Further, result of the serial correlation LM test also shows that no serial correlation among variables at higher $p$ values than 5 per cent significant level. Heteroscedasticity test was employed using white heteroscedasticity test to check whether the error term has constant variance. Accordingly, the model indicates no heteroscedasticity problem, or the error term has constant variance since $p$ value is higher than 0.05 significant level.

Accordingly, the estimated model satisfies with the stationarity of the variables, cointegration, selecting appropriate lag and significance of lag selected, stability of the model and residual tests. Therefore, dynamic analysis of the model is discussed using impulse responses functions and variance decomposition. 

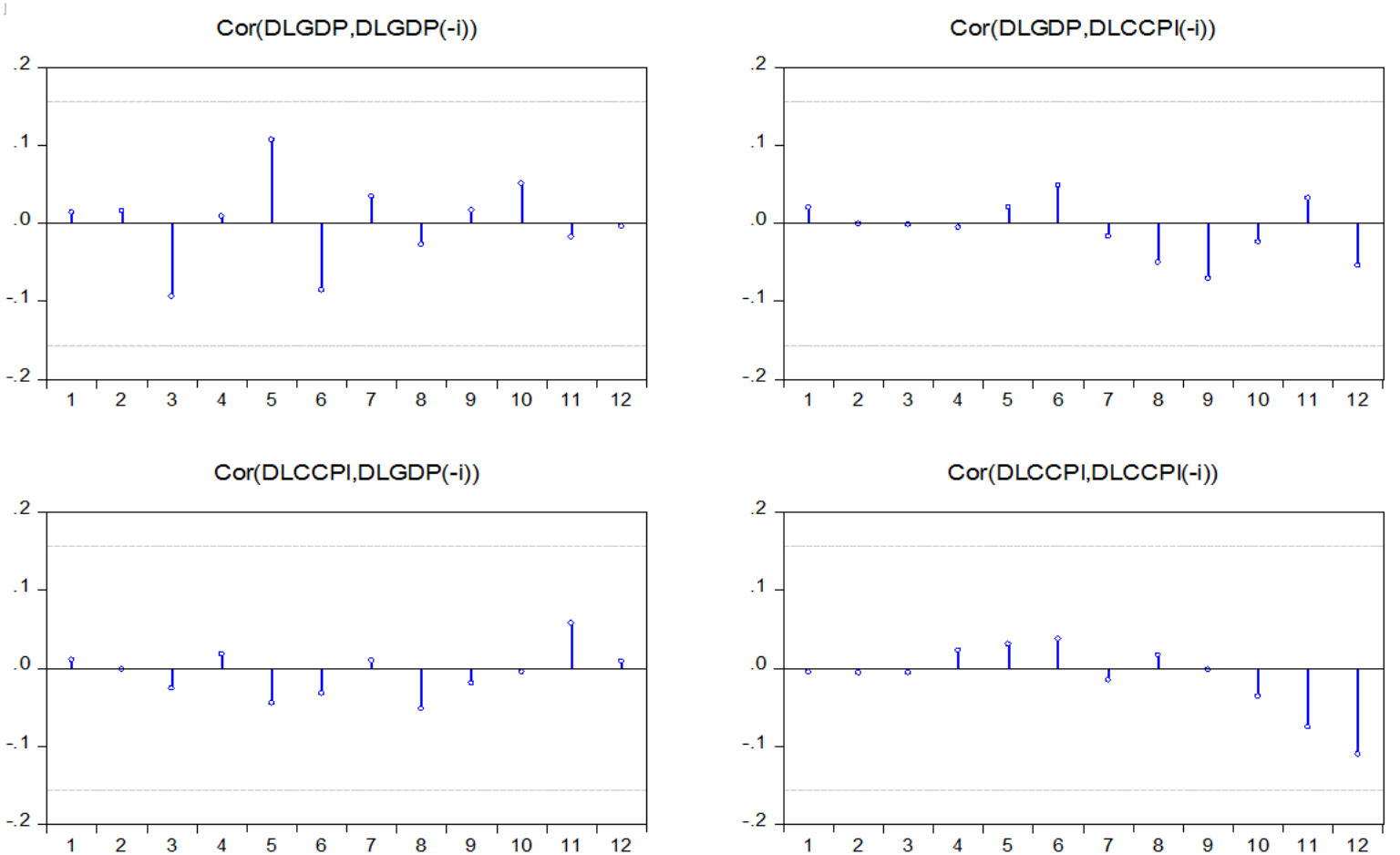

Figure 2. Correlograms; Autocorrelation with approximate 2 standard error bounds.

\begin{tabular}{|c|c|c|c|c|c|c|}
\hline Autocorrelation & Partial Correlation & & $\mathrm{AC}$ & PAC & Q-Stat & Prob \\
\hline.$|. \quad|$ &. $\mid$ & 1 & 0.011 & 0.011 & 0.0197 & 0.888 \\
\hline.$|. \quad|$ &.$|. \quad|$ & 2 & 0.020 & 0.019 & 0.0835 & 0.959 \\
\hline$*|. \quad|$ & $*|. \quad|$ & 3 & -0.079 & -0.079 & 1.1250 & 0.771 \\
\hline.$|. \quad|$ &. $\mid$ & 4 & 0.009 & 0.010 & 1.1384 & 0.888 \\
\hline$.\left.\right|^{*} \quad \mid$ & $.\left.\right|^{*} \quad \mid$ & 5 & 0.085 & 0.088 & 2.3577 & 0.798 \\
\hline$*|. \quad|$ & $*|. \quad|$ & 6 & -0.078 & -0.088 & 3.4110 & 0.756 \\
\hline.$|. \quad|$ &. & 7 & 0.036 & 0.037 & 3.6373 & 0.820 \\
\hline.$|. \quad|$ &. & 8 & -0.032 & -0.016 & 3.8162 & 0.873 \\
\hline.$|. \quad|$ &. $\mid$ & 9 & -0.027 & -0.045 & 3.9459 & 0.915 \\
\hline.$|. \quad|$ &. $\mid$ & 10 & 0.059 & 0.064 & 4.5491 & 0.919 \\
\hline.$|. \quad|$ &. $\mid$ & 11 & 0.003 & 0.011 & 4.5506 & 0.951 \\
\hline.$|. \quad|$ &.$|. \quad|$ & 12 & 0.008 & -0.015 & 4.5615 & 0.971 \\
\hline$*|. \quad|$ & $*|. \quad|$ & 13 & -0.093 & -0.073 & 6.1189 & 0.942 \\
\hline.$|. \quad|$ &.$|. \quad|$ & 14 & 0.001 & 0.005 & 6.1190 & 0.963 \\
\hline.$|. \quad|$ &. $\mid$ & 15 & 0.058 & 0.049 & 6.7313 & 0.965 \\
\hline.$|. \quad|$ &. $\mid$ & 16 & -0.000 & -0.006 & 6.7313 & 0.978 \\
\hline.$|. \quad|$ &. $\mid$ & 17 & -0.043 & -0.049 & 7.0675 & 0.983 \\
\hline.$\left.\right|^{*}$ &.$\left.\right|^{*}$ & 18 & 0.075 & 0.105 & 8.1212 & 0.977 \\
\hline.$|. \quad|$ &. $\mid$ & 19 & 0.005 & -0.010 & 8.1257 & 0.985 \\
\hline.$|. \quad|$ &. $\mid$ & 20 & 0.041 & 0.023 & 8.4388 & 0.989 \\
\hline
\end{tabular}

Figure 3. Correlogram of the residuals.

\subsection{Impulse Response Functions and Variance Decompositions}

In VAR model, results are discussed by means of impulse response functions and variance decompositions. Impulse response function traces out the responses of current and future values of each of the variables to a one unit increase in the current value of one of the VAR errors. Variance decompositions gives the contribution in percentage that gives explanatory ability of each variable. 
Response to Cholesky One S.D. (d.f. adjusted) Innovations \pm 2 S.E.

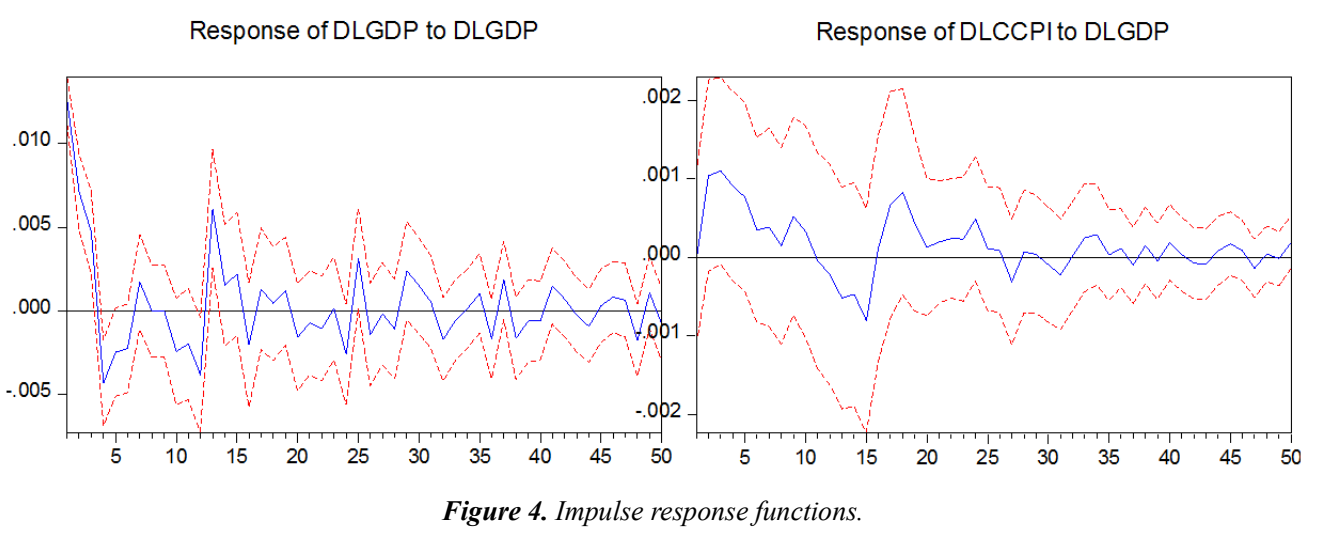

A shock to the growth of LPDCT is impacted to further decline in LPDCT in the short run. The maximum level of declining the growth in LDPCT is up to $4^{\text {th }}$ period, month. Then growth in labour productivity is gradually fluctuated up to 12 months. Again, a sharp increase in labour productivity can be noted after one year period and declining trend in the long run. Therefore, any shock to the growth of labour productivity is directed to establish a lower level of labour productivity from the existing level. Shock in LPDCT is responded by increasing the inflation level in the short run up to $2^{\text {nd }}$ period and then gradually fluctuate price level to end with dying out the shocks in the long run. Therefore, any negative shock to DLPCT is noted to decline LPDCT and established at lower level and rise in inflation in the short.
Further the shocks are dying out gradually throughout the period. Impulses on LPDCT is associated to increase LCCPI in immediate short run while shocks are dying out in long run. This indicates that short run relationship between labour productivity and LCCPI is negative. Negative relationship between inflation and labour productivity has been examined in majority of empirical studies. Therefore, results are in line with empirical findings.

Forecast Error variance decompositions are used to analyses the contribution to the error variance of each variable. It shows the explanatory ability of the considered variable using other variables. Variance decompositions of variables in model one is given below.
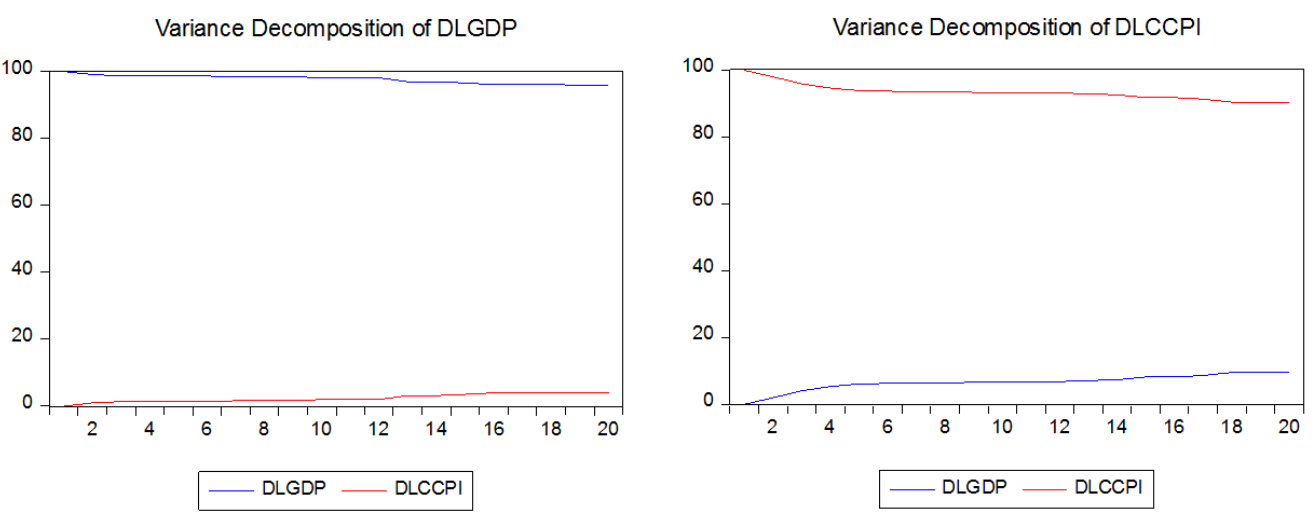

Figure 5. Forecast Error Variance Decompositions.

According to the variance decomposition, DLPDCT is contributed 100 per cent of its variance at period one. Therefore, DLPDCT is identified as strongly endogenous variable in the short run. This endogeneity is declining slightly whilst contribution from inflation is moderated around 6 per cent of error variance in DLPDCT during the period. Error variance of DLCCPI is 99 per cent from variable itself and its gradually declining throughout the period. Contribution from DLPDCT in the error variance of DLCCPI has increased from 1 per cent to 14 percent towards the end of the period. Therefore, a higher contribution of DLPDCT is observed in LCCPI error variance movements, showing the importance of increasing DLPDCT to lower inflation. Both variables indicate as having weak influence on the error variance of each other variable.

\subsection{Causal Relationship Between Inflation and Labour Productivity Growth}

This was tested using pairwise granger causality test for univariate modules. The importance of the causal relationship and the direction of causality has been identified as importance in forecasting purposes. If the causality is identified, the variable can be used to better forecast of other variables than using the variable itself alone. Results of the test are given below. 
Table 5. Results of Pairwise Granger Causality test.

\begin{tabular}{llll}
\hline Null Hypothesis & Observations & F-Statistics & Prob. \\
\hline DLCCPI does not Granger Cause DLPDCT & 163 & 0.85102 & 0.6260 \\
DLPDCT does not Granger Cause DLCCPI & & 0.92490 & 0.5427 \\
\hline
\end{tabular}

Accordingly, the null hypothesis of existence of granger causality between variables are rejected since $p$ value is higher than the 5 per cent significant level. Therefore, this is evident that there is no direction of causality between variables. As per empirical evidences, Granger causality relationship have been examined as one way or two-way relationships from productivity to inflation and vice versa with respect to developed and industrialized countries. Study conducted for Sri Lanka by [34] also examined that there is no causal relationship between inflation and labour productivity for the period from 1966-1977. Therefore, findings are in line with the previous study conducted for Sri Lanka.

\section{Conclusion, Recommendations and Suggestions}

This study was conducted aiming to examine the relationship between inflation and labour productivity in Sri Lanka to fill the identified and existing research gap in literature regarding empirical and methodological aspect. Univariate VAR model is estimated employing quantitative, secondary sourced and monthly data for the period spanning from 2006 to 2020. Labour productivity was constructed using Gross Domestic Production divided by Employed Population, can be identified as a widely used economic and statistical indicator to measure the efficiency and competitiveness of a nation. Inflation, a continuous increase in general price level of a country as measures by price indices, has been identified in theory and empirical studies as a variable that negatively impact on labour productivity in short run. Labour productivity has increased over the period whilst inflation has been volatile following a declining trend. Results of the data analysis indicates a negative relationship between inflation and labour productivity in Sri Lanka.

A univariate VAR model using lag order $16^{\text {th }}$ is estimated for variables that are not cointegrated and stationary at first difference subject to requirement of empirical testing under stability and residual tests. Accordingly, results indicate a negative relationship between inflation and labour productivity in short run, as per the data from 2006 to 2020 . Results are in line with the findings of empirical literature $[23,25-27]$ and further, it has been given, number of reasons for existing negative relationship between inflation and labour productivity. These reasons include declining purchasing power of wages and then less motivation to work, inefficient mix of factor inputs, inefficient investment plans, encourage firms to increase cost on inventories and thereby reduce cost on research and developments. Declining purchasing power of real wages and therefore reducing motivation effort to work has identified as a reason that impact to decrease labour productivity supported by higher inflation in short run. In some studies, it has quantified the relationship [30] as 1 per cent increase in labour productivity reduces inflation by $0.07-0.08$ per cent. In this dynamic analysis, impact of inflation on labour productivity is identified monthly basis with lag effects. Accordingly, 1 per cent increase in LCCPI is associated to decrease labour productivity by 0.0147 per cent in first month period and by 0.3240 per cent significantly in $2^{\text {nd }}$ month period that shows in detail the dynamic movements in impulse response functions. CCPI responses with upward movements on impulses of DLPDCT indicating the negative relationship between variables. Error variance of each variable is contributed less than 10 per cent from the other variables. Further, no granger causal effect between variables is examined which findings are in line with the previous study covered for Sri Lanka from 1966-1997, [34].

Further, estimated model indicates robust results since the analysis was conducted under the requirement of basis test, selecting a lag order criteria, stability and residual test to ensure the appropriateness of the model. Therefore, it can be pointed out that keeping a lower-level inflation is helpful in achieving higher labour productivity. Lower-level inflation will be benefitted to stimulate economic activities and avoid real wage erosion and thereby motivation to work that has been indirectly contributed to the labour productivity. Accordingly, it can be concluded, inflation is an effective policy tool in conducting monetary policy on short run basis.

Recommendations can be made to maintain lower level or single digit inflation to enhance labour productivity as a broadbased measure. As per findings of the literature, inflation benefits to redistribute effect of economic growth in developed countries and industrialized countries compared to developing countries. Further, threshold level of 8-9 percent inflation has been identified to enhance economic growth that benefited to developing countries in many studies conducted for Asian countries. Findings of this study shows a negative relationship between inflation and labour productivity in short run. Therefore, considering all aspects, it can be concluded that inflation can be identified as effective policy tool in conducting monetary policy in Sri Lanka. The effect of lower inflation is positively impact on labour productivity due to improvements in gross domestic product. Therefore, keeping a lower level, less volatile but not stable and single digit inflation is strongly recommended in enhancing economic growth and labour productivity as well. In addition, challenges relating to lower labour force participation ratio, aging population, knowledge and skills gaps in labour force, higher unemployment rate in educated youth and women should be separately addressed to turn labour market towards efficient path. This research can be further improved using other 
variables that can be influenced to enhance labour productivity. Total productivity also can be considered depends on the availability of data.

\section{References}

[1] Krugman, P. R., The age of diminished expectations: US economic policy in the 1990s. 1997: MIT press.

[2] Lucas, R. E., Some international evidence on output-inflation tradeoffs. The American Economic Review, 1973. 63 (3): p. 326-334.

[3] Hendry, D. F., Modelling UK inflation, 1875-1991. Journal of applied econometrics, 2001. 16 (3): p. 255-275.

[4] Freeman, D. G. and D. B. Yerger, Does inflation lower productivity? Time series evidence on the impact of inflation on labor productivity in $12 \mathrm{OECD}$ nations. Atlantic economic journal, 2000. 28 (3): p. 315-332.

[5] Paul, S., C. Kearney, and K. Chowdhury, Inflation and economic growth: a multi-country empirical analysis. Applied Economics, 1997. 29 (10): p. 1387-1401.

[6] Asian Development Bank, International Labour Organization, and Regional Office for Labour the Pacific, Sri Lanka: fostering workforce skills through education: employment diagnostic study. 2017.

[7] Pruchnik, K. and J. Zowczak, Middle-income trap: Review of the conceptual framework. 2017, ADBI Working Paper.

[8] Gokal, V. and S. Hanif, Relationship between inflation and economic growth. Vol. 4. 2004: Economics Department, Reserve Bank of Fiji Suva.

[9] Sarel, M., Nonlinear effects of inflation on economic growth. Staff Papers, 1996. 43 (1): p. 199-215.

[10] Eggoh, J. C. and M. Khan, On the nonlinear relationship between inflation and economic growth. Research in Economics, 2014. 68 (2): p. 133-143.

[11] Burdekin, R. C., et al. When does inflation hurt economic growth? in Different Nonlinearities for Different Economies. Available as a Claremont Working Paper at $<\mathrm{http}: / /$ spe. cgu. edu/institutes/conference/mainindex. html. 2000.

[12] Behera, J., Inflation and its impact on economic growth: Evidence from six South Asian countries. Journal of Economics and Sustainable Development, 2014. 5 (7): p. 145154.

[13] Mallik, G. and A. Chowdhury, Inflation and economic growth: evidence from four south Asian countries. Asia-Pacific Development Journal, 2001. 8 (1): p. 123-135.

[14] Hussain, S. and S. Malik, Inflation and economic growth: Evidence from Pakistan. International Journal of Economics and Finance, 2011. 3 (5): p. 262-276.

[15] Aslam, A. and S. Lebbe, Inflation and economic growth in Sri Lanka: An ARDL bound testing approach. 2017.

[16] Madurapperuma, W., Impact of inflation on economic growth in Sri Lanka. Journal of World Economic Research, 2016. 5 (1): p. 1-7.
[17] Konieczny, J. D., Inflation, output and labour productivity when prices are changed infrequently. Economica, 1990: p. 201-218.

[18] Sinn, H.-W. and M. Reutter, The minimum inflation rate for Euroland. 2001, National Bureau of Economic Research.

[19] Hoogenveen, V. C. and S. K. Kuipers, The long-run effects of low inflation rates. PSL Quarterly Review, 2000. 53 (214).

[20] Feldstein, M., Inflation, tax rules and the accumulation of residential and nonresidential capital. The Scandinavian Journal of Economics, 1982: p. 293-311.

[21] Buck, A. J. and F. Fitzroy, Inflation and productivity growth in the federal republic of Germany. Journal of Post Keynesian Economics, 1988. 10 (3): p. 428-444.

[22] De Gregorio, J., Economic growth in latin america. Journal of development economics, 1992. 39 (1): p. 59-84.

[23] Jarrett, J. P. and J. G. Selody, The productivity-inflation nexus in Canada, 1963-1979. The review of economics and statistics, 1982: p. 361-367.

[24] Smyth, D. J., Inflation and total factor productivity in Germany. Weltwirtschaftliches Archiv, 1995. 131 (2): p. 403405 .

[25] Clark, P. K., Inflation and the productivity decline. The american economic review, 1982. 72 (2): p. 149-154.

[26] Hondroyiannis, G. and E. Papapetrou, Seasonalitycointegration and the inflation, productivity and wage growth relationship in Greece. The social science journal, 1997. 34 (2): p. 235-247.

[27] Wakeford, J., The productivity-wage relationship in South Africa: an empirical investigation. Development Southern Africa, 2004. 21 (1): p. 109-132.

[28] Christopoulos, D. K. and E. G. Tsionas, Productivity growth and inflation in Europe: Evidence from panel cointegration tests. Empirical Economics, 2005. 30 (1): p. 137-150.

[29] Narayan, P. and R. Smyth, The effect of inflation and real wages on productivity: New evidence from a panel of G7 countries. Applied economics, 2009. 41 (10): p. 1285-1291.

[30] Kim, S., H. Lim, and D. Park, Does productivity growth lower inflation in Korea? Applied Economics, 2013. 45 (16): p. 2183-2190.

[31] Tsionas, E. G., Inflation and productivity in Europe: an empirical investigation. Empirica, 2003. 30 (1): p. 39-62.

[32] Bulman, T. and J. Simon, Productivity and inflation. 2003: Reserve Bank of Australia Sydney, Australia.

[33] Mahadevan, R. and J. Asafu-Adjaye, The productivityinflation nexus: the case of the Australian mining sector. Energy economics, 2005. 27 (1): p. 209-224.

[34] Mahadevan, R. and J. ASAFU-ADJAYE, IS THERE A CASE FOR LOW INFLATION-INDUCED PRODUCTIVITY GROWTH IN SELECTED ASIAN ECONOMIES? Contemporary Economic Policy, 2006. 24 (2): p. 249-261.

[35] Sbordone, A. and K. Kuttner, Does inflation reduce productivity? Federal Reserve Bank of Chicago Economic Perspectives, 1994. 18 (6): p. 2-14. 
[36] Cameron, N., D. Hum, and W. Simpson, Stylized facts and stylized illusions: inflation and productivity revisited. Canadian Journal of Economics, 1996: p. 152-162.

[37] Freeman, D. G. and D. B. Yerger, Inflation and multifactor productivity growth: a response to Smyth. Applied Economics Letters, 1998. 5 (5): p. 271-274.

[38] Hondroyiannis, G. and E. Papapetrou, Temporal causality and the inflation-productivity relationship: evidence from eight low inflation OECD countries. International Review of Economics \& Finance, 1998. 7 (1): p. 117-135.

[39] Papapetrou, E., The inflation and productivity relationship in Poland. Journal of Economics and business, 2003. 2003 (2): p. 11-33.

[40] Gujarati, D. N., Basic econometrics. 2009: Tata McGraw-Hill Education.
[41] Granger, C. W., P. Newbold, and J. Econom, Spurious regressions in econometrics. Baltagi, Badi H. A Companion of Theoretical Econometrics, 1974: p. 557-61.

[42] Freeman, R., Labour productivity indicators: Comparison of two OECD databases productivity differentials \& the BalassaSamuelson effect. Retrieved from OECD Statistics Directorate Web site: http://www. oecd. org/dataoecd/57/15/41354425. pdf, 2008.

[43] Engle, R. F., D. F. Hendry, and J.-F. Richard, Exogeneity. Econometrica: Journal of the Econometric Society, 1983: p. 277-304.

[44] Engle, R. F. and C. W. Granger, Co-integration and error correction: representation, estimation, and testing. Econometrica: journal of the Econometric Society, 1987: p. 251-276.

[45] Liew, V. K.-S., Which lag length selection criteria should we employ? Economics bulletin, 2004. 3 (33): p. 1-9. 